\title{
Cryotherapy for cervical lesions: efficacy and patient satisfaction
}

\section{Shriraj Katakdhond*, Padmaja Samant}

Department of Obstetrics and Gynecology, Seth Gordhandas Sunderdas Medical College, Mumbai, Maharashtra, India

Received: 11 May 2017

Accepted: 16 May 2017

\section{*Correspondence:}

Dr. Shriraj Katakdhond,

E-mail: dr.shrirajsk@gmail.com

Copyright: (c) the author(s), publisher and licensee Medip Academy. This is an open-access article distributed under the terms of the Creative Commons Attribution Non-Commercial License, which permits unrestricted non-commercial use, distribution, and reproduction in any medium, provided the original work is properly cited.

\begin{abstract}
Background: Vaginal discharge is a distressing commonplace gynecological condition seen in all age groups albeit from different causes. This study evaluates the outcome of cryotherapy on benign cervical lesions over a period of 2 years in a tertiary care centre. Efficacy of cryotherapy in making patient symptom free. Efficacy of cryocauterization in healing the cervical lesion.

Methods: This is prospective observational study of 30 women of reproductive age group attending outpatient department for complaint of vaginal discharge. Cervical cytology was performed for all women and out of the women advised cryotherapy, those fitting inclusion criteria and consenting for study were enrolled. Their findings and investigations were noted. After they underwent cauterization, they were followed for period of 3 months. Findings, complications and level of satisfaction were noted down.

Results: Healing of cervical lesion was complete in $96 \%$ women at the end of 12 weeks. There was 1 failure of therapy among sample size of 30 . Satisfaction rate was high.

Conclusions: Cervical cryocauterization is a cheap, effective and simple procedure for treatment of cervical lesions. There are few complications and patient satisfaction is high. It is an easily accessible and safe procedure and helps preserve fertility of women at the same time addressing the vaginal discharge.
\end{abstract}

Keywords: Benign cervical lesions, Cryocauterization, Cervical erosion

\section{INTRODUCTION}

Vaginal discharge is one of the most common yet distressing and awkward symptoms for women. It irritates physically, embarrasses sexually and, tires and scares mentally. Ectropion is a hormone dependent condition and is one of the prime causes of discharge besides cervicovaginal infection. Prevalence of ectropion varies between $14-15 \%$ outpatients. ${ }^{1}$ With lower cell mediated immunity, glandular epithelium creates facilitatory environment for infections with fertility implications as well as carcinogenic implications and also potentially carcinogenic infections like human papilloma virus. ${ }^{2,3}$ Ectropion has been found to be associated with intraepithelial neoplasia in around $17 \%$ cases. $^{4}$
Cauterization of tissues is an age-old method employed to stop bleeding and destroy growth of harmful cells. Cervical lesions have been cauterized chemically with silver nitrate and thermally by electrocautery and cold cautery.

Cryotherapy is the use of low temperatures locally or generally in medical therapy. Its goal when using extreme temperatures is to destroy cells by crystallizing the cytosol. Cryosurgery was introduced to gynaecology in the late 1960 s to treat cervical intraepithelial neoplasia and it is proven to be a reliable treatment modality, with limited side effects and morbidity. The method is used to treat cervical, vaginal, endometrial and vulvar lesions. In cervical cryotherapy, cells destroyed by freezing are shed 
afterwards in a watery discharge. Liquid nitrogen as well as carbon dioxide has been used in cervical cryocauterization. The technique has been acceptable to women and practitioners; it is a low-cost technique and can be easily adapted to local needs. Sankaranarayanan et al have shown that it can be used to see and treat by trained nurses in low resource settings. ${ }^{5}$

\section{METHODS}

This was a prospective observational study. Ethics committee clearance was taken. The cases were selected from the patients of an outpatient department of a tertiary care hospital.

The inclusion criteria were patient with age less than 40year-old but more than 18 years old with cervical erosion or premalignant cervical lesion (CIN 1 and 2) those seeking conservative management. Consent was taken when the treating physicians advised cryotherapy for cervical lesions.

The exclusion criteria were as follows

- Active genital tract infection

- Adenocarcinoma

- CIN 3

- Large lesions

- Lesions extending into cervical canal

- Exophytic lesions

- Cytology not matching with colposcopy women unwilling for cryotherapy

Cases were from all socio-economic groups. Thirty cases were enrolled.

\section{History}

- Detailed history of abnormal vaginal bleeding and discharge was noted.

- Sexual history and history of being treatment for sexually transmitted diseases and reproductive tract infections was noted. Note was made of the treatment taken in the past for the same. Age of first sexual intercourse was noted.

- Menstrual history, obstetric history and history of relevant past medical and surgical illness was noted. History of contraceptive use was noted.

\section{Physical examination and investigations}

Speculum examination was done to note site of cervical lesion, size of lesion and any other associated cervical pathology. Vaginal examination was done to assess the size, shape, mobility of uterus and to rule out adnexal pathology. Preoperatively exfoliative cytology, HIV, VDRL tests were done in all cases. Consent for cryocauterization was taken. Patients with signs of pelvic or vaginal infections underwent treatment with syndromic approach.

The cryogenic device consisted of a gas tank containing a refrigerant and non-explosive, non-toxic gas. Nitrous Oxide gas was used in this study. The gas is delivered using flexible tubing through a gun-type attachment to the cryoprobe.

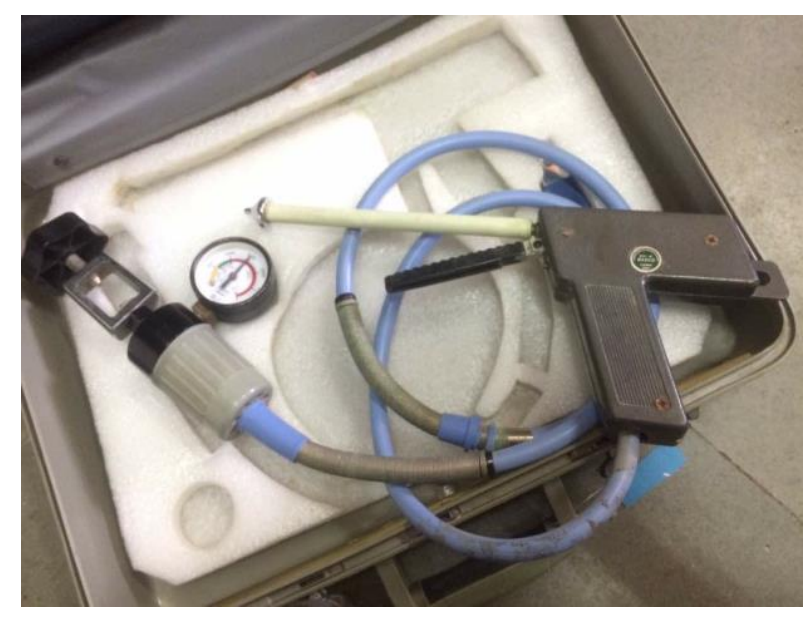

Figure 1: Apparatus.

\section{Procedure}

- The procedure was performed during post menstrual period.

- Depending upon size, appropriate cryoprobe was selected. A cryoprobe was placed in contact with the cervix and the system was activated.

- An iceball was allowed to develop upto a $5 \mathrm{~mm}$ lateral spread beyond the lesion. The Freeze time of the cryocauterization is 3 minutes and the thaw time was 5 minutes. If the lesion was too large, multiple applications were made. The system was deactivated and the probe was allowed to separate from the frozen cervical tissue.

- The patients were explained that they may experience a heavy watery discharge for the first month after cryotherapy resulting from the sloughing of dead tissue and exudate from the treatment site. They were explained about possibility of mild cramplike pain and were told to report if fever, heavy bleeding or severe pain occurred. Patients were discharged the same day.

- The patients were asked to refrain from sexual intercourse and tampon use for 6 weeks after cryotherapy to avoid infection and bleeding and to allow re-epithelisation of the cryolesion. Prophylactic antibiotics were given for 5 days to all women.

\section{RESULTS}

The largest number of patients belonged to age group between 26-30 years followed by $31-35$ years 


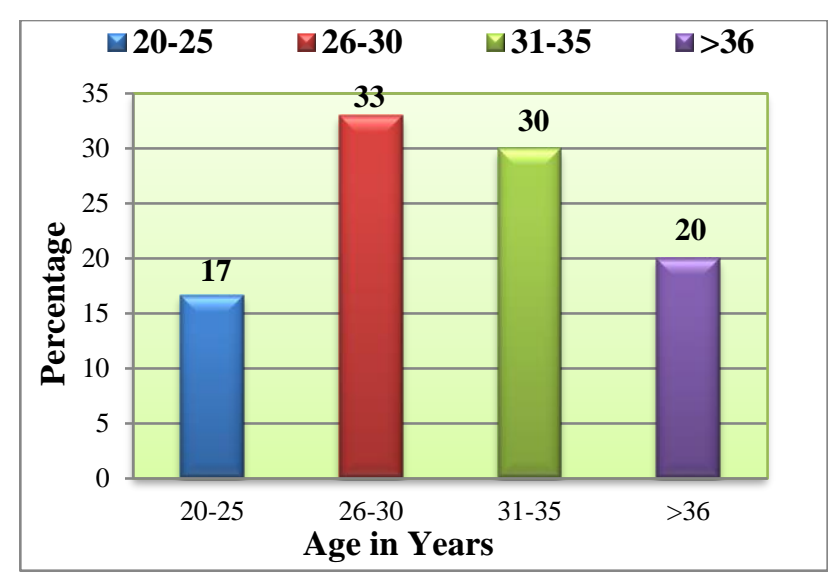

Figure 2: Age distribution of patients.

The largest number of patients were multiparous $(87 \%)$. There were no nulliparous patients.

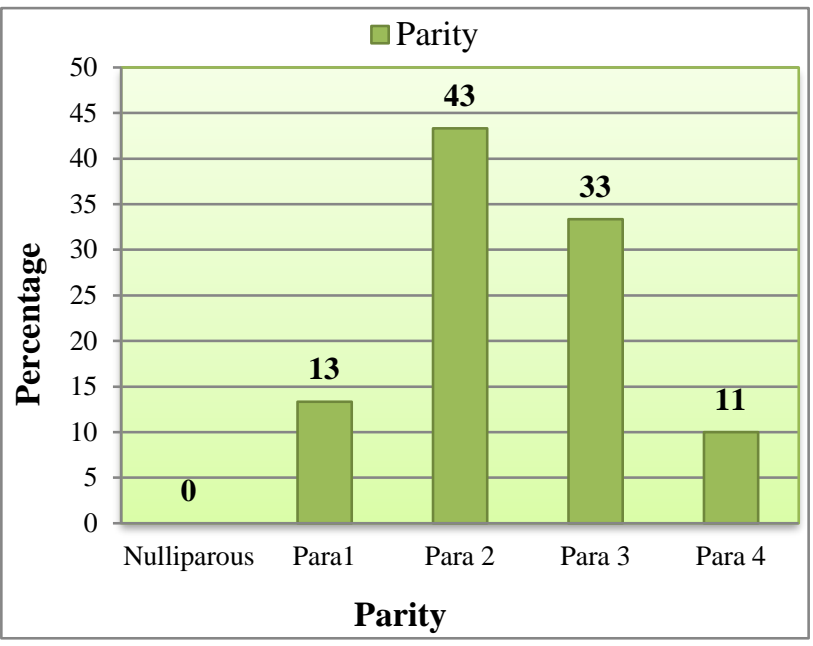

Figure 3: Parity distribution.

All patients were HIV and VDRL negative.

Table 1: Chief complaints.

\begin{tabular}{|lll|}
\hline Chief complaints & No. of cases & $\%$ \\
\hline Abnormal vaginal discharge & 30 & 100 \\
\hline Abnormal vaginal bleeding & 4 & 13 \\
\hline Menstrual irregularity & 2 & 7 \\
\hline Pelvic and/or abdominal pain & 10 & 33 \\
\hline Backache & 5 & 17 \\
\hline
\end{tabular}

Table 2: Cytological findings.

\begin{tabular}{lll} 
cytological findings & No. of cases & $\%$ \\
Mild inflammatory & 20 & 67 \\
\hline Severe inflammatory & 07 & 23 \\
\hline Inflammatory with infection & 02 & 07 \\
LSIL & 1 & 03
\end{tabular}

Abnormal vaginal discharge was the commonest complaint. Followed by pelvic or abdominal discomfort.
Two thirds of the patients had sought treatment for complaint of discharge without success.

One case showed low grade squamous intraepithelial lesion. Two cases showed presence of the organism such as bacterial vaginosis along with inflammatory changes which were treated before procedure.

Table 3: Immediate complication.

\begin{tabular}{lll} 
Immediate Complication & No. of cases & $\%$ \\
\hline No Complication & 24 & 80 \\
\hline Pain / discomfort & 5 & 17 \\
\hline Bleeding & 0 & 00 \\
weakness & 01 & 03 \\
\hline
\end{tabular}

\section{Immediate Complication}

Five cases (17\%) had mild discomfort or mild pain in abdomen (uterine cramp). One case $(3 \%)$ experienced weakness.

Table 4: Complaints in post cauterisation follow up.

\begin{tabular}{|lll|}
\hline After effect (2 week) & No. of cases & $\%$ \\
\hline Watery discharge & 25 & 83 \\
\hline Pain & 3 & 10 \\
\hline Bleeding & 1 & 3 \\
\hline weakness & 1 & 3 \\
\hline
\end{tabular}

\section{Watery discharge hydrorrhea}

(Hydrorrhea) was most common complaint of the patients. Pain: occasional and mild pain was present in 3 cases relieved by analgesic.

\section{Bleeding}

Bleeding was present in one case, after examination it was found to be due to incomplete treatment, as the cervical lesion was large. One patient who had pain complained of weakness.

Table 5: Follow up duration.

\begin{tabular}{|lll}
\hline Follow up at weeks & No. of cases & $\%$ \\
\hline 2 weeks & 28 & 93 \\
\hline 2 and 6 weeks & 24 & 80 \\
\hline 2,6 and 12 weeks & 24 & 80
\end{tabular}

In present study, follow up was $93 \%$ at 2 weeks but at the end of 12 weeks, 5 patients were lost to follow up and one patient had failure of the procedure.

\section{Failure}

In present study, one patient had bleeding per vaginum was found to have a large cervical lesion which was not 
cauterised properly. She was termed as a failure of procedure.

\section{Satisfaction}

On questioning, directly about satisfaction with procedure all patients except the two; the one with postcauterization bleeding and the other with weakness reported satisfaction at symptom relief.

\section{DISCUSSION}

Cervical ectropion (or cervical erosion) is a condition in which the central (endocervical) columnar epithelium protrudes out through the external os of the cervix and onto the vaginal portion of cervix. The everted epithelium has a reddish appearance similar to the granulation tissue, and may be covered by a yellow turbid discharge. Though benign it is a distressing condition for women and with low cellular immune response the tissue can facilitate harmful viral infections like HIV and HPV.

Cervical cryotherapy is a procedure, which involves freezing an area of abnormal tissue on the cervix. This tissue gradually disappears and the cervix heals.

\section{Mechanism of action of cryotherapy}

The physical effect of cryotherapy is known as "direct cell injury". At freezing temperature, water crystallizes in the extracellular spaces and in turn leads to cellular dehydration called as "solution-effect injury". Cells shrink and membranes and cellular components are damaged.

During thawing, ice melts, the extracellular environment rapidly becomes hypotonic allowing water to enter within the damaged cells, causing cell membrane disruption. Lowering the temperature weakens cell scaffolding and causes mechanical damage, $\mathrm{pH}$ decrease, consequently lead to metabolism failure.

Vascular stasis and cellular anoxia followed by hyperperfusion and oxidative damage occurs due to vasoconstriction and vasodilatation due to freezing and thawing. And eventually results in cell sloughing.

\section{Factors affecting success of therapy}

- The number of freeze/thaw cycles

- Holding (duration of freezing)

- The mass of frozen tissue

- The nature of tissue: Cancer cells are very cryosensitive

- The distance from the probe.

In this study, the failed case probably could have benefitted with multiple applications.

\section{Advantages}

- Serious injuries or complications are rare

- It is quick and easy, short time

- No hospitalization needed

- No anaesthesia is required

- Simple and inexpensive equipment

- There is minimal blood loss due to a sealing off effect on the frozen tissue

- It is the less expensive than Laser

- There is no need of electricity

- Cervical stenosis or rate of pregnancy is not altered

- It can be used in cases of blood dyscrasias.

\section{Disadvantages}

- Discharge which is usually profuse, watery and may last for 2-3 weeks.

- Uterine cramping i.e. pain, often occurs during the cryotherapy but rapidly subsides after treatment, may last for 36 hours.

- Vasomotor reaction in form of flushing, dizziness, headache, can occur during procedure.

- Due to friability of treated area, contact bleeding may occur so intercourse should be avoided for 3-4weeks.

- Vaginal and vulval burns.

Liquid nitrogen is by far the most popular cryogen due to the low temperatures achievable $\left(-197^{\circ} \mathrm{C}\right)$, which make it suitable for both benign and malignant lesions. Carbon dioxide still enjoys some popularity. Szemesi I, Matányi $\mathrm{S}$, Scömör S Jr found $95 \%$ healing in 8 weeks by cryocoagulation in cervicitis resistant to conservative therapy. ${ }^{6}$ Hurt WG successfully used cryotherapy in treatment of mild and moderate dysplasia of the ectocervix and chronic cervicitis. ${ }^{7}$ Konnegen and colleagues found cure rate was $92 \%$ that after a single cryosurgery, and $98 \%$ after a second application. ${ }^{8}$ Baram et al recommended that infertile patients with hostile cervical mucus and ectropion will be treated by cryosurgery. ${ }^{9}$ Present study did not have any infertile patients. Wojtys $\mathrm{A}$, Zdebski $\mathrm{Z}$ reported complete recovery in the form of typical stratified squamous epithelium in $95.3 \%$ of cases. ${ }^{10}$ Matanyi $\mathrm{S}$ observed in 1248 cervical cryosurgeries that side effects (hypogastric discomfort, vascular reactions) were negligible; profuse vaginal discharge was present following the treatment. ${ }^{11}$

In our series 24 patients had no complaints in the immediate post procedure period, 5 had mild pelvic discomfort treated with antispasmodic medication. No one had bleeding in the immediate post procedure period.

One patient complained of weakness that resolved on rest and was probably unrelated to the procedure. $\mathrm{R}$ Sankaranarayanan and colleagues from India, concluded that 'see and treat' with cryotherapy by nurses under medical supervision is acceptable, safe and effective method for cervical cancer prevention in low-resource 
settings. ${ }^{5}$ Mariategui $\mathrm{J}$ and co-workers have stated that CO2-cryotherapy may be less effective than $\mathrm{N}_{2} \mathrm{O}$ cryotherapy for complete destruction of cervical precancerous lesions. ${ }^{12}$

In present study, the age of the patients varied between twenty to forty years. Cervical erosion was found maximum in women with age group twenty-six to thirty. Four studies presented results stratified by age group.

One randomized trial and two follow-up studies compared cure rates for women divided into categories younger or older than 30 years of age. ${ }^{13-15}$ Results from Guijon suggest that older women were less likely to fail therapy, although the difference was not statistically significant. ${ }^{16}$

In present study, most of the patients were multiparous. Guijon found that neither the number of pregnancies $(p=0.07)$ nor the number of live births $(p=0.49)$ were significantly associated with treatment failures for cryotherapy or laser ablation combined. ${ }^{16}$ Kwikkel reported a slightly higher cure rate for nulliparous women (91 percent) versus that for multiparous women (85 percent). ${ }^{13}$

In present study, majority of cases were from lower socioeconomic status contributing to 70 percent. But this may be due to the fact that the institute predominantly caters to urban lower income groups. There was no selection bias and patients were enrolled serially as they were offered the therapy.

Our findings are comparable to those of Kulkarni and Durge Lower literacy, early sexual activity and high parity are contributory for the occurrence of cervical erosion. ${ }^{17}$

Table 6: Location of cervical lesion.

\begin{tabular}{|lll|}
\hline Lesion & Cases & $\%$ \\
\hline Circumoral & 18 & 60 \\
\hline Anterior & 5 & 17 \\
\hline Posterior & 5 & 17 \\
\hline Mucosal Polyp and anterior erosion & 2 & 6 \\
\hline
\end{tabular}

Table 7: Age of first sexual intercourse.

\begin{tabular}{|lll|}
\hline Age of first sexual intercourse (Years) & Cases & $\%$ \\
\hline $15-16$ & 04 & 13 \\
\hline $17-18$ & 11 & 37 \\
\hline $19-20$ & 06 & 20 \\
\hline $21-22$ & 04 & 13 \\
\hline $23-25$ & 02 & 07 \\
\hline$>26$ & 03 & 10 \\
\hline
\end{tabular}

In present study, $50 \%$ of cases had their first sexual intercourse at age less than 18 years, which explain one of the causes for cervical erosion.
Table 8: Complaints and finding among patients.

\begin{tabular}{|lllll|}
\hline Study & $\begin{array}{l}\text { Vaginal } \\
\text { discharge }\end{array}$ & Infection & Pain & Bleeding \\
\hline KC Mohanty & $90 \%$ & $22 \%$ & $32 \%$ & $16 \%$ \\
\hline $\begin{array}{l}\text { Gay C, Riehl } \\
\text { C }\end{array}$ & $92.30 \%$ & $6.20 \%$ & $4.60 \%$ & $21.50 \%$ \\
\hline $\begin{array}{l}\text { Present } \\
\text { study }\end{array}$ & $100 \%$ & $7 \%$ & $33 \%$ & $13 \%$ \\
\hline
\end{tabular}

Vaginal discharge was the main complaint in this study. Incidence of pain and irregular bleeding in present study is comparable with study by Mohanty. ${ }^{18}$ In present study, $7 \%$ of cases had local infection; $67 \%$ cases were treated as syndromic approach with antibiotic therapy by the treating clinicians. 17 patients received secnidazole $1 \mathrm{gm}$ with fluconazole $150 \mathrm{mg}$ in a single dose for vaginal discharge syndrome. 3 patients received cefixime $400 \mathrm{mg}$ single dose with metronidazole $400 \mathrm{mg}$ and doxycycline $100 \mathrm{mg}$ twice daily for 14 days for lower abdominal pain, as syndromic treatment before cryosurgery. ${ }^{19-21}$

Table 9 compares the healing rates in various studies. In present study $96 \%$ cases, healed by cryotherapy and is comparable with most studies.

Table 9: Efficacy according to healing of cervical lesion.

\begin{tabular}{|l|l|}
\hline Study & Healing \\
\hline Peck & $91 \%$ \\
\hline Szemesi & $97 \%$ \\
\hline Mohanty & $98 \%$ \\
\hline Wojtys & $95.30 \%$ \\
\hline Alvarez & $92 \%$ \\
\hline Guijon & $94.60 \%$ \\
\hline Gay & $95.20 \%$ \\
\hline Present study & $96 \%$ \\
\hline
\end{tabular}

Limitations of the study was small sample size. Paucity of diverse indications like CIN1 which can study the treatment effectiveness of procedure.

\section{CONCLUSION}

The study concludes that socio-economic factors such as low literacy status, early age at marriage and high parity are contributory factor for the occurrence of cervical erosion.Cervical erosion is associated with reproductive tract infection. $67 \%$ of cases were advised syndromic treatment by clinicians for reproductive tract infections. The rate of symptomatic relief was high. All these patients were treated without local anesthesia and they found the procedure acceptable and satisfaction with symptomatic relief was high. Cryotherapy is one of the best methods to treat symptomatic cervical ectropion. It is a technique, which is easy to acquire and practice. It is completely painless for women. Cryosurgery is a cheap, easy, and safe treatment suitable for both hospital and office based practice. Cryotherapy can be performed in an 
ambulatory set up and is regarded as method of choice to treat benign cervical lesions.

\section{ACKNOWLEDGMENTS}

Authors would like to thanks head of the Department Dr. S. V. Parulekar and Dean Dr. A. N. Supe.

Funding: No funding sources

Conflict of interest: None declared

Ethical approval: The study was approved by the Institutional Ethics Committee

\section{REFERENCES}

1. Goldacre M, Loudon N, Watt B. Epidemiology and clinical significance of cervical erosion in women attending family planning clinic. BMJ. 1978;1:74850.

2. Rocha-Zavaleta L, Yescas G, Cruz RM. Human papillomavirus and cervical ectopy. Int $\mathrm{J}$ Gynaecol Obstet. 2004;85:259-66.

3. Louv W, Austin H, Perlman J. Oral contraception use and the risk of chlamydial and gonococcal infections. Am J Obstet Gynecol. 1989;160:360-402.

4. Sarkar P, Steel P. Routine colposcopy prior to treatment of cervical ectopy: is it worthwhile? J Obstet Gynaecol 1996;16:96-7.

5. Sankaranarayanan R. Effectiveness, safety and acceptability of 'see and treat' with cryotherapy by nurses in a cervical screening study in India. $\mathrm{Br} \mathbf{J}$ Cancer. 2007;96(5):738-43.

6. Szemesi I, Matányi S, Scömör S. Use of cryocoagulation in gynecology. Acta Chir Acad Sci Hung. 1976;17(4):317-27.

7. Hurt W. Cryotherapy of the cervix. J Fam Pract. 1979;9(1):109-11.

8. Konnegen V, Heber G, Richter P, Köhler B. Ambulatory cryosurgical restoration of benign cervical lesions. Zentralbl Gynakol. 1984;106(9):611-5.

9. Baram A, Paz G, Peyser M, Schachter A, Homonnai Z. Treatment of cervical ectropion by cryosurgery: effect on cervical mucus characteristics. Fertil Steril. 1985;43(1):86-9.
10. Wojtyś A, Zdebski Z. Effects of low-temperature treatment of pathologic changes of the cervix uteri. Ginekol Pol. 1989;60(5):276-9.

11. Matányi S. Side effects and complications of cervical cryotherapy. Acta Chir Hung. 1992-1993;33(12):157-62.

12. Mariategui J, Santos C, Taxa L, Jeronimo J, Castle PE. Comparison of depth of necrosis achieved by $\mathrm{CO}_{2^{-}}$and $\mathrm{N}_{2} \mathrm{O}$-cryotherapy. Int $\mathrm{J}$ Gynaecol Obstet. Jan 2008;100(1):24-6.

13. Kwikkel H, Helmerhorst $\mathrm{T}$, Bezemer P. Laser or cryotherapy for cervical intraepithelial neoplasia: a randomized study to compare efficacy and side effects. Gynecologic Oncology 1985;22(1):23-31.

14. Andersen E, Husth M. Cryosurgery for cervical intraepithelial neoplasia: 10-year follow-up. Gynecol Oncol. 1992;45(3):240-2.

15. Hemmingsson E. Outcome of third trimester pregnancies after cryotherapy of the uterine cervix. Br J Obstet Gynaecol. 1982;89(8):675-7.

16. Guijon F, Paraskevas M, McNicol P. Human papillomavirus infection and the size and grade of cervical intraepithelial neoplastic lesions associated with failure of therapy. Int $\mathrm{J}$ Gynaecol Obstet. 1993;42(2):137-42.

17. Kulkarni R, Durge. Role of socio-economic factor and cytology in cervical erosion in reproductive age group women. Indian J Med Sci. 2002;56(12):598601.

18. Mohanty K, Rand R, Berry B. Cryotherapy in the management of cervical ectopy. Genitourin Med. 1985;61(5):335-7.

19. Gay C, Riehl C, Ramanah R, Desmoulin G, Violaine B. Cryotherapy in the management of symptomatic cervical ectopy. Gynecol Obstet Fertil. 2006;34(3):214-23.

20. Peck J. Cryosurgery for Benign Cervical Lesions. Br Med J. 1974; 2(5912):198-9.

21. Alvarez B. Cryosurgery of the uterine cervix. Ginecol Obstet Mex. 1991;59:105-11.

Cite this article as: Katakdhond $\mathrm{S}$, Samant $\mathrm{P}$. Cryotherapy for cervical lesions: efficacy and patient satisfaction. Int J Reprod Contracept Obstet Gynecol 2017;6:2331-6. 